\title{
Violence at work in the ambulance service: The role of HRM and other systems
}


It is an unfortunate reality that employees at greatest risk of violence are those working in roles that serve the health and wellbeing of the community (Karaeminogullari, Erdogan, \& Bauer, 2018). Paramedics are especially susceptible to injury as they work in uncontrolled and potentially volatile conditions, compounded by exposure to traumatic events (Bigham et al., 2014). Up to ninety percent of paramedics are exposed to some form of violence (Boyle, Koritsas, Coles, \& Stanley, 2007), leading many to view violence as an unavoidable part of their job (Pourshaikhian, Abolghasem Gorji, Aryankhesal, Khorasani-Zavareh, \& Barati, 2016). Despite a significant number of assault-related injuries, surprisingly little is known about the situational risk factors associated with violence against paramedics (Wongtongkam, 2017).

Work-related violence is defined as any incident whereby a person is abused, threatened, or assaulted (physically, verbally or sexually - including threats) in a scenario pertaining directly to their chosen occupation (Loudoun \& Johnstone, 2019). Violence at work is a problematic and undesirable behaviour affecting employees, colleagues, leaders, HR Managers, and communities and stakeholders more broadly (Karaeminogullari et al., 2018). The impact of violence against paramedics cannot be understated. Paramedics working under threat of violence alongside exposure to traumatic events see increased incidence of exhaustion (Granter, Wankhade, McCann, Hassard, \& Hyde, 2018), depression and anxiety (Izutsu, Tsutsumi, Asukai, Kurita, \& Kawamura, 2004), post-traumatic stress (Bennett et al., 2005), and physical injury rates far higher than other industries (Maguire, O'Meara, Brightwell, O'Neill, \& Fitzgerald, 2014). Flow-on effects for the organisation, additional to the impact on staff performance, include increased employee turnover (Patterson et al., 2010), burnout and long-term sick leave (Brattberg, 2006).

Ensuring employee health, safety and wellbeing typically falls within a HR Department's formal responsibility (Loudoun \& Johnstone, 2019). While this task is complex in most 
organisations, in circumstances where the 'workplace' is not fixed, controlling the situation becomes especially challenging. This article investigates the research problem of violence against employees in such an environment. We examine how the HRM system responds to and manages violence against paramedics in their work lives. Given the complexity of the problem apparent from our data, we incorporate multi-stakeholder (Beer, Boselie, \& Brewster, 2015) and open systems perspectives (Harney, 2019) to identify how other key systems and situational factors interact and address limitations of the HRM system. This article addresses a pertinent HRM problem in a way that responds to calls for improvements to HRM research: to incorporate a focus on contextual factors (Kaufman, 2015); to consider employee wellbeing as a vital outcome of HRM (Guest, 2017); and to do these things from a qualitative, case-based methodology that captures the nuance often over-looked in HR research (Beer et al., 2015).

Building on seminal work by Beer, Spector, Lawrence, Mills, and Walton (1984), we contribute to HRM knowledge through our Conceptual map of HRM and violence in the ambulance sector, and propose a Multi-layer framework of system responses to work-related violence. Practical contributions from this study include improved understanding of risk factors for violence against paramedics, strengths and weaknesses of HRM system-level responses, external system responses addressing HRM limitations, and recommendations for improvements across internal and external systems.

\section{Frontline response: A dangerous work environment}

Paramedics provide life-saving assistance to sick or injured patients as the first response to an emergency. In Australia, around 20,000 salaried ambulance officers and paramedics and over 6000 volunteers collectively respond to more than three million calls for assistance annually (Australian Industry and Skills Committee, 2020; Maguire, 2018). The paramedics' work 
environment, however, is different to most workplaces; each call presents a new place of work requiring constant identification of hazards and risk mitigation (Loudoun \& Johnstone, 2019).

Evidence shows violence in this sector is pervasive, both in Australia and overseas (Coomber et al., 2019; van der Velden, Bosmans, \& van der Meulen, 2016). Risk of serious injury for paramedics is seven times the Australian average (Maguire et al., 2014), owing in combination to the physical nature of the role and to violent assault. Previous research indicates over half emergency responders have been physically assaulted (Gabrovec, 2015; Pourshaikhian et al., 2016); two-thirds verbally assaulted (Bigham et al., 2014); and one quarter sexually assaulted (Gabrovec, 2015).

The reason for such high rates of assault are complex. No single risk factor precipitates violence, rather, an interaction of individual and situational factors compound risk (Wongtongkam, 2017). Employee characteristics such as gender (males are higher risk), age (young and middle-aged cohorts are higher risk), limited work experience, and interpersonal conflict are known risk factors (Hogh \& Viitasara, 2005; van der Velden et al., 2016; Wongtongkam, 2017). Patient behaviours are also central to explaining work-related violence. For example, patients with psychological conditions attribute to increased aggression (see for discussion Pourshaikhian et al., 2016). Substance abuse is another key risk factor (LACLS, 2017); and alcohol is associated with aggression in around half of violent attendances (Coomber et al., 2019). Severe shock, trauma, grief, and responses to pain are also compounding factors.

Linked to the patient's aggressive response are environmental conditions. In a systematic review on studies of workplace violence against emergency medical personnel, Pourshaikhian et al. (2016) found delayed emergency response predisposed aggressive behaviour. Time of work, shift duration, and working conditions predict violence against healthcare workers 
(Viitasara, Sverke, \& Menckel, 2003), and studies of police and paramedics show similar findings (Barrick, Strom, \& Richardson, 2018; Wongtongkam, 2017). Despite pertinence of such factors, the understanding of situational risks for violence is lacking, and there are calls for "qualitative research that can offer deeper investigations of the predisposing factors" (Pourshaikhian et al., 2016: 6). Given the influence of situational hazards on paramedics' physical working conditions, we believe studies of ambulance work (and similar occupations) must consider the work environment that affects the HRM system, and hence we include this in our research design.

\section{HRM system responses to workplace violence}

We are interested in exploring how people are managed when exposure to violence in the work environment is frequent. As HRM researchers, we are initially concerned with understanding how HRM can act to prevent and respond to violence, and understand employees' perspectives of the HRM system's response. Although HRM is critical to managing employee health and wellbeing, there is limited discussion of organisational-level responses to work-related violence in emergency services and similar work (Pourshaikhian et al., 2016).

From a practice perspective, a combination of approaches is key where work-related violence is common. Employee Assistance Programs (EAPs) offer counselling and support for employees and immediate family members. Use of EAPs is standard industry practice in emergency services and healthcare. These programs are directed towards preventative health and wellbeing, to decrease long-term absences, and improve morale and performance (Richmond, Pampel, Wood, \& Nunes, 2017). EAP services are typically outsourced to independent suppliers or managed and implemented independently to core workplace practices (Scully, 2011). 
Additionally, some emergency services organisations facilitate 'peer support programs', whereby employees volunteer for training in mental health and counselling, and support colleagues exposed to trauma. Peer support is effective in reducing stress and incidence of mental health conditions (Scully, 2011). In high trauma positions such as ambulance work, free access to registered psychologists is also common (Kellner, Townsend, Loudoun, \& Wilkinson, 2019b).

Training is a fundamental component for prevention and minimisation of harm from violence. De-escalation skills, including threat perception and defensive training, while typical among law enforcement, is lacking for paramedics (LACLS, 2017). Resilience training (e.g., stress management techniques, cognitive behavioural therapy) assists to manage/ mitigate negative effects of exposure to traumatic events such as assault (Anderson, Vaughan, \& Mills, 2017). Absence or inadequacy of formal training has been highlighted in many studies (see Pourshaikhian et al., 2016 for a review). Compounding this, limited training is provided to student paramedics by tertiary institutions, and training during induction and on-the-job is also reportedly inconsistent (Boyle \& Wallis, 2016).

Following traumatic events, debriefing to address critical incident stress has seen widespread use across high risk occupations (Mitchell \& Everly, 1995; Scully, 2011). Debriefing is a facilitated discussion immediately following an event, examining facts, observations and personal emotional responses (Mitchell \& Everly, 1995). Reviews of the approach are mixed, and there is limited understanding about the usefulness of debriefing following assault against paramedics. In sum, we outline key HRM practices identified as components of an HRM system which must respond to and manage violence against employees. While these are a central part of our research focus, "we gain a limited picture by collecting information on HR practices without paying full attention to the context within which they are enacted" (Guest, 
2011: 6). In the following section, we consider strategic HRM literature that will help us piece together these HRM system components in the broader context of the research problem.

\section{Systems, context and HRM: A model}

So far, the review of the research problem indicates situational and individual factors can increase the risk of violence, and organisations make choices about HRM system features to respond to and manage employee exposure. Given the inability of the HR department to control the work environment, we may also need to consider outside influences on employees such as police protection on the scene or union advocacy. We also acknowledge broad reaching consequences of violence for the employee, organisation, patient and community. These key variables surround our research problem.

Much contemporary HRM research strives for 'big data and HR analytics', emphasising development of more sophisticated analytical techniques as the only way forward for the field (Guest, 2011; Jiang \& Messersmith, 2018). Over the last three decades, the discipline has increasingly adopted the "science-based model where organizations and HRM are studied as if in a laboratory...[with an] emphasis on analytic theory development..." (Kaufman, 2015p.398). Research generally adopts a narrow focus on HRM system components (e.g. policy, practices, processes) seeking to quantify their relationship with employee or organisational performance outcomes (Beer et al., 2015; Boxall \& Purcell, 2016). One of a limited selection of theoretical lenses are adopted for this purpose, often directed internally with minimal consideration of antecedents or contextual variables (a detailed summary of theoretical approaches is provided by Jiang \& Messersmith, 2018). Given the lack of extant research into our problem, combined with the importance of understanding the surrounding environment, a typical approach seeking to test theory or relationships, that neglects or assumes away context surrounding the HR problem, would be unsuitable (Beer et al., 2015). 
In this study, we do not assume the HRM system is closed and operating independently from surrounding conditions. Instead, we agree "HRM issues are part of open systems and research is theoretically bankrupt unless placed in the broader context..." (Zedeck \& Cascio, 1984: 463). An open systems perspective, acknowledging HRM systems are influenced by and interact with other systems, is of value particularly where employees conduct work outside physical organisational boundaries (Townsend, Lawrence, \& Wilkinson, 2013). Systems thinking has been applied in studies of HRM to frame research; develop explanatory categories; and as a heuristic device to understand context; as opposed to a theoretical model intended for predictive accuracy (Harney, 2019).

The open systems view overlaps with a multi-stakeholder perspective of HRM. HR practitioners operate in a complex environment where they must interact with stakeholders such as management, unions, and government, and these diverse perspectives will influence choices about HRM (Boxall \& Purcell, 2016). Seminal work by Beer et al. (1984) on the multistakeholder view is based on a 'social systems' perspective, acknowledging "the influence and relevance of multiple stakeholders (internal and external), their social interactions, and their influence on HRM...” (Beer et al., 2015: 429). In what has been generally referred to as the 'Harvard model of HRM', Beer et al.'s classic work identifies situational factors affecting stakeholder interests and HRM policy choices, an approach contrary to some more recent models of HRM which maintain an inward focus and neglect external influences (Kaufman, 2015, 2020).

The Harvard model, although simplistic, is useful to map concepts associated with our research problem - the HRM system, stakeholders/systems, situational components, and potential outcomes. Factors listed in the Harvard model (e.g. situational variables) are noted as indicative not conclusive (Beer et al., 1984), and we seek to develop this model as we examine findings in our study of the ambulance service. We highlight that although Beer et al. and others examine 
HRM in terms of existence of policy, a focus on enacted practices provides a more realistic portrayal of the functioning of the HRM system (Guest, 2011). Importantly, as the Harvard model highlights, outcomes of HRM systems reach beyond one dimensional financial performance measures typically examined, and we consider implications of HRM decisions for employee and societal wellbeing (Guest, 2017). This work provides a holistic conceptual lens to help us understand violence against employees in their broader work environment.

In this study, we do not seek scientism (Kaufman, 2020) or generalisability, rather we examine a unique context and seek to understand- the relationships and interactions - that can only be uncovered through detailed qualitative research. We now focus on our guiding research questions:

How does the HRM system manage and respond to the problem of violence against employees in their work environment?

How do other key systems and situational factors contribute to our understanding of the problem of violence against employees in their work environment?

\section{Methods}

This study is based on findings of a larger mixed-methods project conducted across three Australian cases. Each case refers to an entire state ambulance service, operating across metropolitan, rural and extremely remote and indigenous areas. The cases are provided the following pseudonyms and vary in size as follows: North Service ( $<1000$ employees), South Service $(<3000)$ and East Service $(<5000)$. Together, the services handle around one-and-ahalf million cases annually, including emergency and crisis planning and response, pre-hospital care, and inter-hospital transport. At North Service, the government appointed a third-party organisation as provider of ambulance services, while other cases are state-run. 
By area, East Service is largest, and comprises a major metropolitan capital city, and a combination or regional, rural, remote and indigenous populations. South Service is similarly comprised but less populous. North Service has low population density, mostly comprised of remote and indigenous locations.

Access was gained through the associated industry union. Union access is appropriate as South and North cases have 99 percent union density, and East has 70 percent density. A criterion sampling strategy was adopted for interviews (Patton, 2014), with the key criterion that participants were current employees. Recruitment for employee interviewees was initiated from union newsletters and email. Senior management interviews were arranged directly with participants.

The research project included 1216 telephone surveys and 72 interviews, complemented by both internal and publicly available secondary documents. Surveys measured employees' experiences of work, lifestyle and health factors. Interviews provided better understanding of nuanced issues and participant experiences. Secondary data included organisational, HRM and employee support strategy and planning documents, policies, procedures, and independent assessor reports. This article draws primarily upon qualitative data as is most suited to answering the research questions. We present some basic statistical data from surveys to demonstrate prevalence of workplace assault in our sample. Other, more in-depth examinations of our quantitative data are published elsewhere (reference removed for blind review).

Interviews were conducted with a selection of volunteer and deliberately requested senior managers, team leaders, ambulance staff (majority of interviews), communications officers, patient transport officers, and union officials. Participants were chosen to ensure variation in employees, gender, level of experience and location (rural vs metropolitan). Appendix 1 presents a list of interviewee titles and numbers as cited following quotes in findings. A semi- 
structured interview protocol was developed, focussing on key themes rather than strict questioning. This approach enabled interviewers to create an informal atmosphere and allow interviewees to raise and explore topics (Patton, 2014).

Interviews were audio recorded and transcribed professionally. Transcripts, field notes and electronic documentary evidence were input into NVivo whereby a two-step coding process was followed (for discussion see Patton, 2014). Analysis involved reading and re-reading data and assigning keywords (second-order categories) to passages of text to facilitate sorting and identification of emerging themes (first-order categories). Next, a process of creating, deleting, merging and dividing themes and categories occurred until agreement about final categories was reached within the team. Randomly selected sections of coded data were crosschecked by team members throughout the process to test internal reliability with a high level of consistency. Final codes were categorised according to situational risk factors, other organisational systems (external organisations, industry level and state/federal level), core HRM system features, and violence outcomes.

\section{Findings}

We begin by presenting some statistical data from our surveys, as noted in the Methods, which establishes high levels of assault among our sample. Exposure to assault is similar to previous research and higher in some areas. Almost 32 per cent of our cohort faced physical assault frequently, while another 56 per cent report they 'rarely' faced to physical assault approximately an 88 per cent exposure rate - compared with others (Gabrovec, 2015; Pourshaikhian et al., 2016) reporting more than 50 per cent. Bigham et al. (2014) found around two thirds of paramedics had been verbally assaulted, while our cohort reported a rate of almost 98 per cent. Both the Gabrovec and Pourshaikhian studies found around 25 per cent of paramedics faced sexual assault while our results suggest around 60 per cent. Boyle et al. 
(2007) suggests 90 per cent of paramedics are exposed to some form of violence during work, and our figures reflect this position (see Table One for all results).

\section{[TABLE 1]}

\section{Conceptual map of HRM and violence in the ambulance sector}

We adapt Beer et al.'s Harvard model of HRM to structure our findings, presented in the Conceptual map of HRM and violence in the ambulance sector (Figure 1). Building on their multi-stakeholder approach, we adopt a similar systems view of multi-level systems that influence choices about HRM. Next, we include situational factors from the data, drawing some from the Harvard model (e.g. workforce characteristics), and some modifications based on the data (e.g. media influence, patients/bystanders on scene). We note a delineation between immediate situational factors impacting the work environment (the first three factors) and factors in the broader societal context (the last three factors).

Given our focus on employee experiences of HRM practice (rather than existence of policy), we adapt the model accordingly (amending HRM policy choices to HRM practices). We also update the model to suggest situational factors and systems can have two-way relationships with HRM practices. This means some practices can affect key systems, for instance, a weak bundle of HRM practices reduces staff capability, increasing pressure on key systems (e.g. unions, police) to reduce violence or mitigate its effect. Similarly, a strong bundle of practices could improve staff capability, influencing situational factors (such as workforce characteristics, and improved de-escalation of risks in physical environment). 


\section{[FIGURE 1]}

In the next section we explore elements of the Conceptual Map, beginning with key systems, situational variables, then HRM practices. We conclude by reviewing some examples of negative HRM and long-term outcomes raised by interviewees, highlighting practical implications for paramedics.

\section{Key systems}

Our findings suggest multiple external systems interact with, support and supplement the HRM system to prevent and respond to violence. Examples of these systems and interactions are provided throughout the findings, and first summarised here. Figure two illustrates our conceptualisation of other system interactions with the HRM system, and outside influence of situational risk factors, in a Multi-layer framework of system responses to work-related violence.

[FIGURE 2]

As illustrated, the HRM system is the initial and central source of employee support. Beyond this there is support through external organisations. One of these is tertiary institutions, some of which educate students in violence de-escalation. Another key organisation is psychological services co-ordinated by the HR Department to provide assistance to employees. Also, as many interviewees highlight, there is the critical role for police, often called to provide security for paramedics. 
Industry level systems include unions, representative bodies and inter-organisational taskforces and committees. These systems provide higher-level monitoring and response to violence. For example, a large multi-industry union provides legal support and advocacy for paramedics. Unions often partner with universities to collect data and report on paramedic working conditions and exposure to violence. Taskforces and committees, some supported by the union, have investigated and provided recommendations on escalating violence (e.g. LACLS, 2017). These systems are instrumental in collecting data on violence and campaigning for prevention and better protections.

Industry level systems feed into federal and state level systems, which adopt increasingly interventionist roles in preventing and responding to assaults. To deter and reduce violent behaviour, some states have implemented legislation imposing heavier gaol penalties for persons that physically assault paramedics. Another state-level response has been media advertising campaigns to raise public awareness of the issue and effect of violence, influencing societal values and behaviours. Over the last decade, campaigns messages have included: Zero Tolerance; No excuse for abuse; Respect our staff; Keep your hands off our ambos, and; It's never $O K$. Analysis of these campaigns indicates a short term reduction in reported incidents, although results are not necessarily sustained (LACLS, 2017). As many perpetrators of violence against paramedics are influenced by drugs, alcohol, or psychological illness, they are unlikely to be in the frame of mind to reasonably consider penalties as a deterrent.

In short, we identify a multi-layered system dealing with violent behaviours in the ambulance service. This involves high-level government and industry investigations, protections and campaigns; lower-level external support systems; and intra-organisational systems including HRM at the core. Each system does not provide complete coverage hence reliance upon multiple systems. 


\section{Situational factors}

Situational risk factors relate to the environment in which paramedics work. Broader societal risk factors (legislation, societal values/ behaviours, and media) are inextricably linked with their associated state and federal key systems and were highlighted accordingly in the previous section. Immediate risk factors are associated with physical environmental conditions and individuals (the paramedics, patients, their associated persons, and bystanders) within it. The organisation and HRM system have greater control over immediate than the broader societal risk factors, and we examine these in greater detail.

Patients and bystanders pose a significant assault risk to paramedics. Consistent with evidence from government and academic sources (Coomber et al., 2019; LACLS, 2017), participants reported drugs and alcohol as central to most assaults. There were many references to increased methamphetamine use and associated aggressive and unpredictable behaviour.

We are getting a lot of drug abuse that we weren't getting 15 years ago or even 10 years ago. We are getting a lot more drug use. A lot of ice. 4

They've gone off from the cannabis, into the methamphetamines and things. Even the young children 14, 15, 16... People change. They can be nice as pie one minute and then three seconds later they want to rip your head off. 36

The injury occurred because a drunk woman had tried to fall off the stretcher. And I didn't try and catch her, but she's wrenched my arm as she's tried to fall. 9

Paramedic work involves considerable manual handling, associated with a high rate of physical injury (Maguire et al., 2014). However, as the previous quote indicates, drug and alcohol abuse 
Where you've got community violence... paramedics then have to try and separate these people while they're trying to care for them and stuff. That's where you can get a lot of assaults of the paramedics. Some areas they get police now come in, before the paramedics come in, due to the high violence. 18

As this interviewee notes, paramedics can be sent to a scene to care for a patient, however, violent behaviour can prevent access. Once they have treated the patient and moved them to the ambulance, violence may continue within this enclosed space, enhancing the risk of injury.

[Paramedics] go into an environment that is not controlled, could have danger... Then you're bringing these people into your ambulance which has got a restricted capacity to move around... you need police assistance. 6

We had been sent to a job with a patient who was a psych patient. We weren't told the police were there. They had someone under arrest and of course the police are as stretched as we are in [remote town]. They put the patient into our ambulance. He appeared okay, so they left. As soon as they left the scene, he started rocking and getting abusive and shouting. We were so frightened we jumped out of the ambulance and rang Comms and said, we need the police back here straight away. Well, there were no police available to come back. 21

The previous interviewee highlights the unpredictability of patient behaviour, and the pertinence of police assistance. Paramedics cannot directly control the situation or individual and must seek support from another organisational system. There are limits to paramedic's 
ability to protect themselves, as they are not equipped in the same way as other emergency services such as police:

We don't have capsicum spray. We don't have a gun or a baton. We're not allowed to do anything to harm a patient... Sometimes we are in situations where we're actually at more of a risk and that's shown with the statistics on how many ambo's get assaulted. 38

As noted earlier, certain workforce characteristics are associated with increased incidence of assault against employees, such as gender, age and amount of work experience (Hogh \& Viitasara, 2005; van der Velden et al., 2016; Wongtongkam, 2017). In this study, participants reported concern for young paramedics while clinically and academically capable had limited experience dealing with violent behaviour and situations.

I've been in with new students to some quite big psych jobs and you can just see the fear in them. 25

The young guys find it very hard and they've got aggressive patients, they stand in front of them and read them the riot act, well... you've got to address [patients] with a certain amount of respect or they're going to punch you. 23 In the first three years, you know, I'd get assaulted probably two, three times a year because I just didn't talk to people well and... had more of an ego. 35 We've had people assaulted up there quite a lot... I don't know if the younger [paramedics] are probably as street smart. 36

Paramedics with a longer career talked about developing innate awareness of danger, even before an act of violence had occurred. The following examples illustrate how paramedics use this sense of danger to protect themselves and colleagues: 
[A colleague] might just turn around and say something, that you go, uh-oh, that's the alarm bell, time to get out of here. "I'm just going to go get the pink kit", is one of the expressions that we use. We don't have a pink kit. That means, get the hell out of the house, because it's about to go pear-shaped. 32

Ninety per cent of this job is actually talking to people and sussing them out... you can just pick up a shit load by the first couple of words that come out of their mouth. You start to develop a profile on how you're going to react, which way they're going to swing. 34

Despite this all paramedics indicated while there is sometimes an unexplainable sense of danger, there are also more tangible situational factors such as suburbs or properties where the risk of violence and assault is established:

There are definitely suburbs that you wouldn't want to go there without a police escort... You get a sense as you drive up to the property and they're over-grown and you've got the cars on the grass without tyres or doors. 9

These results indicate paramedics consider age and experience provide them with important skills to detect subtle cues that a patient, bystander or situation is becoming dangerous, and in response implement preventative strategies to avoid violence, such as exiting (to retrieve the 'pink kit'), contacting police, or de-escalation techniques. However, 'intuitive' responses can only safeguard them in certain situations, and a combination of controls from other systems is required to manage environmental risks. We explore this multi-layered response as part of the HRM system. 


\section{HRM system features}

The first layer of response and protection of employees is the HRM system. Analysis of barriers to accessing HRM support mechanisms, the effectiveness of these mechanisms, and the intervening role of line managers, has been discussed in the ambulance service context elsewhere (references removed for blind review). The choices HR Managers make about which practices to adopt and how they are implemented are made even more critical given potential consequences involved. Here we discuss key features of HRM practices for managing incidents of violence against paramedics in our cases.

\section{Employee training}

Training is a key practice to assist employees to manage violent situations and effects (LACLS, 2017). At the time of the study, there was no organisation wide violence de-escalation training in place (ad-hoc training existed at some stations). Such training is also not typically part of the tertiary curriculum. Given evidence one third of student paramedics are exposed to violence during clinical placements (Boyle \& McKenna, 2017) there has been a call for educational institutions to better prepare students for such scenarios (Boyle \& Wallis, 2016), and some interviewees recognised the value it could bring to quality of care provided:

My latest lot of students that have come out, two young fellows in their early 20 s went to psych patients, women probably in their early 50s. These are not women who are not easy to deal with because they're smart and they're manipulative and they're angry. These young men just had it down pat. ... Like because they just had the right language, they were assertive but not aggressive... Encouraging. They get training at university. One of the students had actually spent time in a psych ward for a week. Oh my god, and just had it down pat. 25 
The onus for developing soft skills for managing violence and its effects generally falls on employing organisations. South and East Service offered a half-day program focussed on mental health topics pertinent to ambulance work. There were some ongoing activities following the program whereby participants journaled about work experiences and the resulting impact on mental and physical health. East Service also provided managers with a one-day training session on managing resilience and psychological wellbeing. At the time of research, North Service did not offer comparable training, managers indicating this was due to limited resourcing.

\section{Peer and psychologist support}

The HRM system in these cases also offers a peer support program for employees. When a paramedic is identified (by the communications team, colleagues or managers) as involved in a violent or particularly traumatic incident, this triggers a peer support officer to contact them to 'check in'.

\section{Every occupational violence incident gets notified into [the peer support system] so that they can do a touch base. So, we cover it from many angles. 64}

Additional to peer support, employees have free access to psychologists or counsellors. Psychologist and peer support aim to intervene immediately following exposure to an event, before maladaptive coping mechanisms become established, and has high levels of success in treatment and prevention of related conditions (Scully, 2011). Access to support was restricted to some employees in rural and remote regions, particularly at North Service. Where support mechanisms do not exist, this may increase incidence of mental health outcomes following assault. 


\section{Debriefing}

Debriefing following exposure to violent or traumatic incidents is intended to provide education about the individual's thought process and emotions, to identify and respond to the need for additional support, and enable positive rehabilitation (Mitchell \& Everly, 1995).

Debriefs are generally done when they identify certain incidents... It's not compulsory. Then they will go through the case and see what they did well, what they could have done better. 27

Debriefs are described as uncommon in all cases. Interviewees expressed that debriefs are difficult to co-ordinate, particularly given increasing workloads. Also, they are often perceived as poorly managed, and only implemented when necessary to find someone to blame:

The critical incident stress debriefing I'd say is a right debacle. It's just not managed or orchestrated well. It's very difficult to get the entire key players in the same area at the same time. 7

Normally you find they're persistent with debriefs if it looks like it's going to be a coroner's case or something like that, because they need to look at where they can start to shift the blame. 20

Accordingly, following violence we find informal conversations (i.e. a less structured debrief) between paramedic and supervisor more common. Communication with a supervisor following a traumatic incident is important for emotional processing, identifying necessary recourse such as psychological assistance or leave requirements, and determining next steps if the paramedic is going to press criminal charges (Kellner et al., 2019b). 


\title{
Consequences of violence
}

The final two variables in Figure 1 outline HRM outcomes and long-term consequences associated with the HRM response to violence against employees. There are of course positive outcomes of effective HRM other supporting systems, however, the following examples illustrate some negative outcomes and consequences experienced by paramedics when the systems (in Figure 2) fail to prevent or effectively manage the impact of violence at work. These examples help us appreciate the far-reaching effect of traumatic and violent incidents on paramedics.

\author{
He locked himself in a room for seven days straight and drunk himself into \\ oblivion. Lost his wife, lost his kids. He's now a stark raving, functioning \\ lunatic, but he went and worked out in the mines for two years because he \\ just couldn't associate himself with [the ambulance service]. 51
}

Sometimes I feel like I'm in remission and I'm doing well... It's like a cancer. I have to get myself treated and continue to treat my own self, or else it's going to grow into this big, awful, PTSD thing. 35

Participants report the threat of physical or sexual violence can be as traumatic as an actual incident, and trigger a severe response, as the previous interviewee continues:

There was this mountain of a man who had just been in jail multiple times. Could really just kill me. He goes; "Oh, do you want to see my gun?" The fear of that is horrendous.... 35

Physical injuries are more easily identifiable and appear to be reported more than mental conditions. The following interviewees detail their experiences: 


\section{Having my first injury [from an intoxicated patient] this year - I've had to have time off work for it. And getting older, 12 years in the job. All of those things have started whittling away the resilience. 9 \\ The [patient] looked inside the bag and for whatever reason didn't like what was in the bag and turned to [female colleague] and just punched her in the side of the head and dropped her. She's got neck damage. 48}

Consistent with other studies, our findings indicate assault has severe consequences for the individual (Karaeminogullari et al., 2018). Violence also affects the victim's family, their colleagues, ongoing employment, and their financial situation, among other outcomes. HR outcomes as injury, absence, capability to perform work, and resilience, are compounded by longer term consequences for workforce capability, quality of care, and high costs associated with illness and injury (Maguire, 2018). Beyond these traditional metrics, and often overlooked in HRM literature (Guest, 2017), are arguably far greater consequences for employee wellbeing (e.g. psychological and physical impairment) and consequentially, societal wellbeing (e.g. effect of impaired paramedic working in community). Only through this holistic perspective can we understand the significance of the problem, and the importance of fully understanding the risks and responses to violence against paramedics.

\section{Discussion}

This special issue examines deviant and problematic behaviours at work, and our study focusses on violence against employees in an ever-changing work environment. Where work is not performed in one location - such as law enforcement, military, or fire and emergency response - the HR Department has reduced control over ensuring a safe work environment (Loudoun \& Johnstone, 2019). However, there is limited understanding of the role and limitations of the HR Department in this context; the role of other systems or stakeholders in 
addressing HR's limitations; or broader contextual features pertinent to these interactions and relationships. As detailed herein, our study makes original contributions to these underresearched topics, through mapping our findings on HRM, other systems, context, and outcomes associated with violence against paramedics in their work environment. Important practical implications are then discussed, followed by limitations and recommendations for future studies.

\section{Theoretical implications}

The primary contribution of this study is to use a holistic and contextualised perspective of HRM to improve understanding of the problem and potential responses to violence against paramedics. To frame our study, we adapt the Harvard model of HRM (Beer et al., 1984), a classic model which has lasting theoretical and practical value (Boxall \& Purcell, 2016; Kaufman, 2015). Through our use of the Harvard model we present a Conceptual map of HRM and violence in the ambulance sector. Retaining the fundamental structure, we develop components of the model as shown in Figure 1: all variables in each box are revised to reflect variables from our findings; we reconceptualise 'stakeholders' as interacting and open 'systems' (Harney, 2019) to more accurately reflect our findings; and suggest HRM practices may influence situational factors and key systems (inserting a two-way arrow between these variables), such as de-escalation training enabling an employee to effectively defuse aggression at the frontline, thus altering the characteristics of the physical environment. The Conceptual Map provides an overview of our comprehensive findings and distils them in a unique and straightforward way.

Our findings highlight the importance of examining the relationship between the HRM system and other related systems (Townsend et al., 2013) and we expand on this through the Multilayer framework of system responses to work-related violence. We depict an HRM system that attempts to manage and respond to an employee health and safety issue but cannot do so 
effectively. The HRM system cannot deal entirely with the issues as the work environment is unpredictable and impossible to control. This is not HR system failure, rather, the problem requires a multi-layered approach, with several systems working simultaneously to address situational influences (as illustrated). As we discuss further in the practical implications, despite the layered approach, gaps remain in these systems, leading to negative consequences described by interviewees. Unlike much of the HRM literature concerned only with organisational performance outcomes (for examples see review by Jiang \& Messersmith, 2018) we contribute to deeper understanding of factors associated with HRM and outcomes for employee and societal wellbeing (Beer et al., 2015; Guest, 2017). In all, the Conceptual map and Multi-layer framework build on existing HRM theory and knowledge to offer a new conceptualisation of the role of HRM relates to other systems where violence affects employees outside of the workplace.

Additional to contributions to the HRM field, our findings support growing evidence paramedics in Australia and overseas are at very high risk of physical, verbal, and sexual assault (Boyle \& Wallis, 2016; van der Velden et al., 2016). Our article responds to calls for deeper understanding and qualitative research on situational risk factors for violence against paramedics and similar occupational groups (Pourshaikhian et al., 2016; Wongtongkam, 2017). We extend this body of literature by linking these risk factors back to the HRM field and other critical systems, allowing researchers and practitioners to more clearly understand the problem and potential solutions.

\section{Practical and policy implications}

This article considers situational factors associated with assault against paramedics. Patients, bystanders and situational risks include drug and alcohol abuse, community (including domestic) violence, psychological illness, limitations of police support, physical hazards (e.g. confined space), and are exacerbated by inability of paramedics to physically defend 
themselves. Consistent with other studies, youth and limited work experience were associated with increased exposure to violence for paramedics (van der Velden et al., 2016; Wongtongkam, 2017).

Trauma resilience education, violence de-escalation training, peer support, psychological and counselling support can assist paramedics to manage violence and its effects. Existence of wellresourced and quality systems assist employees to process and rehabilitate from violence and trauma (Kellner, Townsend, Loudoun, Dao-Tran, \& Wilkinson, 2019a; Kellner et al., 2019b), or in the case of de-escalation training, potentially reduce the incidence of assault. As noted by others (Boyle \& Wallis, 2016), inconsistencies exist in training (resilience and de-escalation) for paramedics and students during tertiary study. Interviewees acknowledge the value of training prior to workforce entry, particularly given identification of age and limited experience as a risk factor. We strongly support the call for increased de-escalation training in Australia (see for instance, LACLS, 2017) as we saw little evidence of its existence in our cases. Without it, young paramedics, highly clinically competent, but without life experience or skills in aggression management, could be a risk to themselves, colleagues and patients.

Phasing out of clinical debriefs is unsurprising given increasing paramedic workloads. Rather than argue for reintroduction, we acknowledge constraints on management, and recognise informal support can bridge the gap left by formal debriefs (Kellner et al., 2019a). It is important to note we identified variation in HRM systems and support between and even within states and territories, compounded by differences in management styles, staffing, workloads and resourcing. Hence, what is perceived as baseline support in some cases may not even be available in others. Scope for improvement outside existing support mechanisms include enhanced communications for warning police in remote areas, anti-duress alarms in vehicles, and restraint options for aggressive patients (Maguire, 2018). 
There are gaps in the HRM system, and the role of other systems is highlighted in the findings. Police, our interviewees emphasised, are critical to ensuring safety at the scene and enabling paramedics to do their work. Also, is the role of tertiary institutions in training students, and external psychological support. Beyond these organisations, are unions and representative bodies, combined with state and federal powers, that can initiate higher-level change. In recent years there have been investigations, research projects and committee reports informing the debate, with a range of recommendations (e.g. Queensland Paramedic Safety Taskforce, Ambulance Performance and Policy Consultative Committee Victoria). We highlight the importance of ongoing public education (particularly the role of bystanders in de-escalation and contribution to violence, see LACLS, 2017:41), increased funding into evidence-based risk reduction interventions and collaborative research projects (Maguire, 2018; Wongtongkam, 2017).

\section{Limitations and future research}

Our study examined a research problem specific to paramedics, where work is performed outside a workplace and the environment cannot be controlled. These findings do not apply to most workplaces, although many concepts relate to law enforcement, fire response, and some healthcare occupations (e.g. in-home care). While we acknowledge limitations of generalisability of case research, it is valuable where limited extant research exists, as contextualised data can provide deep theoretical understanding of the problem (Patton, 2014).

This study garnered rich insight of individual experiences, although, we acknowledge the victim's account of assault may not always be objective or accurate. Observational research, or analysis of footage from paramedic body cameras, could address this shortcoming. Further, although we reported some common situational risk factors for violence, there remains a need for more thorough identification to assist design of violence interventions in organisations and by other key systems (e.g. Coomber et al., 2019; Wongtongkam, 2017). Workplace violence is 
problematic across emergency services and the healthcare industry, and future research in these sectors may find greater complexity to extend the findings presented here. We encourage higher-level interviews with government representatives, policymakers and key industry players to build a more holistic understanding of the challenges of managing work-related violence and possibilities for change and improvement in the future. 


\section{References}

Anderson, G. S., Vaughan, A. D., \& Mills, S. 2017. Building personal resilience in paramedic students. Journal of Community Safety and Well-Being, 2(2): 51-54.

Australian Industry and Skills Committee. 2020. Industry Overview: Ambulance and Paramedic. https://nationalindustryinsights.aisc.net.au/industries/health/ambulanceand-paramedic, Accessed May 18, 2020.

Barrick, K., Strom, K. J., \& Richardson, N. 2018. Individual and situational influences on injurious assaults against the police. Policing: An International Journal, 41(2): 202214.

Beer, M., Boselie, P., \& Brewster, C. 2015. Back to the future: Implications for the field of HRM of the multistakeholder perspective proposed 30 years ago. Human Resource Management, 54(3): 427-438.

Beer, M., Spector, B. A., Lawrence, P. R., Mills, D. Q., \& Walton, R. E. 1984. Managing Human Assets. New York: The Free Press.

Bennett, P., Williams, Y., Page, N., Hood, K., Woollard, M., \& Vetter, N. 2005. Associations between organizational and incident factors and emotional distress in emergency ambulance personnel. British Journal of Clinical Psychology, 44(2): 215-226.

Bigham, B. L., Jensen, J. L., Tavares, W., Drennan, I. R., Saleem, H., Dainty, K. N., \& Munro, G. 2014. Paramedic Self-reported Exposure to Violence in the Emergency Medical Services (EMS) Workplace: A Mixed-methods Cross-sectional Survey. Prehospital Emergency Care, 18(4): 489-494.

Boxall, P., \& Purcell, J. 2016. Strategy and human resource management (fourth edition). London: Palgrave.

Boyle, M., Koritsas, S., Coles, J., \& Stanley, J. 2007. A pilot study of workplace violence towards paramedics. Emergency Medicine Journal, 24(11): 760-763. 
Boyle, M., \& McKenna, L. 2017. Paramedic student exposure to workplace violence during clinical placements-A cross-sectional study. Nurse Education in Practice, 22(1): 9397.

Boyle, M. J., \& Wallis, J. 2016. Violence against paramedics-when will it stop? Australasian Journal of Paramedicine, 13(1): 2202-2204.

Brattberg, G. 2006. PTSD and ADHD: underlying factors in many cases of burnout. Stress and Health, 22(5): 305-313.

Coomber, K., Curtis, A., Vandenberg, B., Miller, P. G., Heilbronn, C., Matthews, S., Smith, K., Wilson, J., Moayeri, F., \& Mayshak, R. 2019. Aggression and violence at ambulance attendances where alcohol, illicit and/or pharmaceutical drugs were recorded: A 5-year study of ambulance records in Victoria, Australia. Drug and Alcohol Dependence, 205(Article ID 107685): Available Online Only.

Gabrovec, B. 2015. The prevalence of violence directed at paramedic services personnel. Obzornik Zdravstvene Nege (Slovenia), 49(4): 284-294.

Granter, E., Wankhade, P., McCann, L., Hassard, J., \& Hyde, P. 2018. Multiple Dimensions of Work Intensity: Ambulance Work as Edgework. Work, Employment and Society, 33(2): 280-297.

Guest, D. E. 2011. Human resource management and performance: still searching for some answers. Human Resource Management Journal, 21(1): 3-13.

Guest, D. E. 2017. Human resource management and employee well-being: Towards a new analytic framework. Human Resource Management Journal, 27(1): 22-38.

Harney, B. 2019. Systems theory: forgotten legacy and future prospects, Elgar Introduction to Theories of Human Resources and Employment Relations: 112-127: Edward Elgar Publishing. 
Hogh, A., \& Viitasara, E. 2005. A systematic review of longitudinal studies of nonfatal workplace violence. European Journal of Work and Organizational Psychology, 14(3): 291-313.

Izutsu, T., Tsutsumi, A., Asukai, N., Kurita, H., \& Kawamura, N. 2004. Relationship between a traumatic life event and an alteration in stress response. Stress and Health, 20(2): 6573.

Jiang, K., \& Messersmith, J. 2018. On the shoulders of giants: A meta-review of strategic human resource management. The International Journal of Human Resource Management, 29(1): 6-33.

Karaeminogullari, A., Erdogan, B., \& Bauer, T. N. 2018. Biting the hand that heals: mistreatment by patients and the well-being of healthcare workers. Personnel Review, 47(2): 572-591.

Kaufman, B. E. 2015. Evolution of strategic HRM as seen through two founding books: A 30th anniversary perspective on development of the field. Human Resource Management, 54(3): 389-407.

Kaufman, B. E. 2020. The real problem: The deadly combination of psychologisation, scientism, and normative promotionalism takes strategic human resource management down a 30-year dead end. Human Resource Management Journal, 30(1): 49-72.

Kellner, A., Townsend, K., Loudoun, R., Dao-Tran, T.-H., \& Wilkinson, A. 2019a. Balancing Formal and Informal Support for Psychological Health in Emergency Services, Critical Perspectives on the Management and Organization of Emergency Services: 232-287.

Kellner, A. K., Townsend, K., Loudoun, R., \& Wilkinson, A. 2019b. Barriers to frontline manager support for high-trauma workers. Personnel Review, 48(1394-1409). 
LACLS. 2017. Legislative Assembly Committee on Law and Safety, Violence against emergency services personnel, New South Wales Parliament, Sydney. https://www.parliament.nsw.gov.au/committees/inquiries, Accessed 18 May 2020.

Loudoun, R., \& Johnstone, R. 2019. Health, Safety and Well-being, The SAGE Handbook of Human Resource Management [2nd Edition]: 291-316: Sage.

Maguire, B. J. 2018. Violence against ambulance personnel: a retrospective cohort study of national data from safe work Australia. Public Health Research and Practice, 28(1): Available Online Only.

Maguire, B. J., O'Meara, P. F., Brightwell, R. F., O'Neill, B. J., \& Fitzgerald, G. J. 2014. Occupational injury risk among Australian paramedics: an analysis of national data. Medical Journal of Australia, 200(8): 477-480.

Mitchell, J. T., \& Everly, G. S. 1995. Critical incident stress debriefing (CISD) and the prevention of work-related traumatic stress among high risk occupational groups. In G. S. Everly, \& J. M. Lating (Eds.), Psychotraumatology: The Springer Series on Stress and Coping: 267-280. Boston, MA: Springer.

Patterson, P. D., Jones, C. B., Hubble, M. W., Carr, M., Weaver, M. D., Engberg, J., \& Castle, N. 2010. The longitudinal study of turnover and the cost of turnover in EMS. Prehospital emergency care : official journal of the National Association of EMS Physicians and the National Association of State EMS Directors, 14(2): 209-221.

Patton, M. Q. 2014. Qualitative Research and Evaluation Methods. Thousand Oaks: Sage Publications.

Pourshaikhian, M., Abolghasem Gorji, H., Aryankhesal, A., Khorasani-Zavareh, D., \& Barati, A. 2016. A Systematic Literature Review: Workplace Violence Against Emergency Medical Services Personnel. Archives of Trauma Research, 5(1): Available Online Only. 
Richmond, M. K., Pampel, F. C., Wood, R. C., \& Nunes, A. P. 2017. The impact of employee assistance services on workplace outcomes: Results of a prospective, quasiexperimental study. Journal of Occupational Health Psychology, 22(2): 170.

Scully, P. J. 2011. Taking care of staff: A comprehensive model of support for paramedics and emergency medical dispatchers. Traumatology, 17(4): 35-42.

Townsend, K., Lawrence, S. A., \& Wilkinson, A. 2013. The role of hospitals' HRM in shaping clinical performance: a holistic approach. The International Journal of Human Resource Management, 24(16): 3062-3085.

van der Velden, P. G., Bosmans, M. W., \& van der Meulen, E. 2016. Predictors of workplace violence among ambulance personnel: a longitudinal study. Nursing Open, 3(2): 9098.

Viitasara, E., Sverke, M., \& Menckel, E. 2003. Multiple risk factors for violence to seven occupational groups in the Swedish caring sector. Industrial Relations, 58(2): 202-231.

Wongtongkam, N. 2017. An exploration of violence against paramedics, burnout and posttraumatic symptoms in two Australian ambulance services. International Journal of Emergency Services, 6(2): 134-146.

Zedeck, S., \& Cascio, W. F. 1984. Psychological issues in personnel decisions. Annual Review of Psychology, 35(1): 461-518. 
Table 1: Workplace assault exposure from an Australian sample $(n=1216)$

\begin{tabular}{clr} 
Assault type & Frequency & n (percent) \\
\hline \multirow{2}{*}{ Verbal assault } & Never & $15(2.2)$ \\
& Rarely & $129(18.8)$ \\
& Frequently & $542(79.0)$ \\
\hline \multirow{2}{*}{ Physical assault } & Never & $84(12.2)$ \\
& Rarely & $383(55.8)$ \\
& Frequently & $219(31.9)$ \\
\hline \multirow{2}{*}{ Assault with a } & Never & $203(29.6)$ \\
weapon & Rarely & $348(50.7)$ \\
& Frequently & $135(19.7)$ \\
\hline \multirow{2}{*}{ Sexual assault } & Never & $267(38.9)$ \\
& Rarely & $342(49.9)$ \\
& Frequently & $77(11.2)$
\end{tabular}




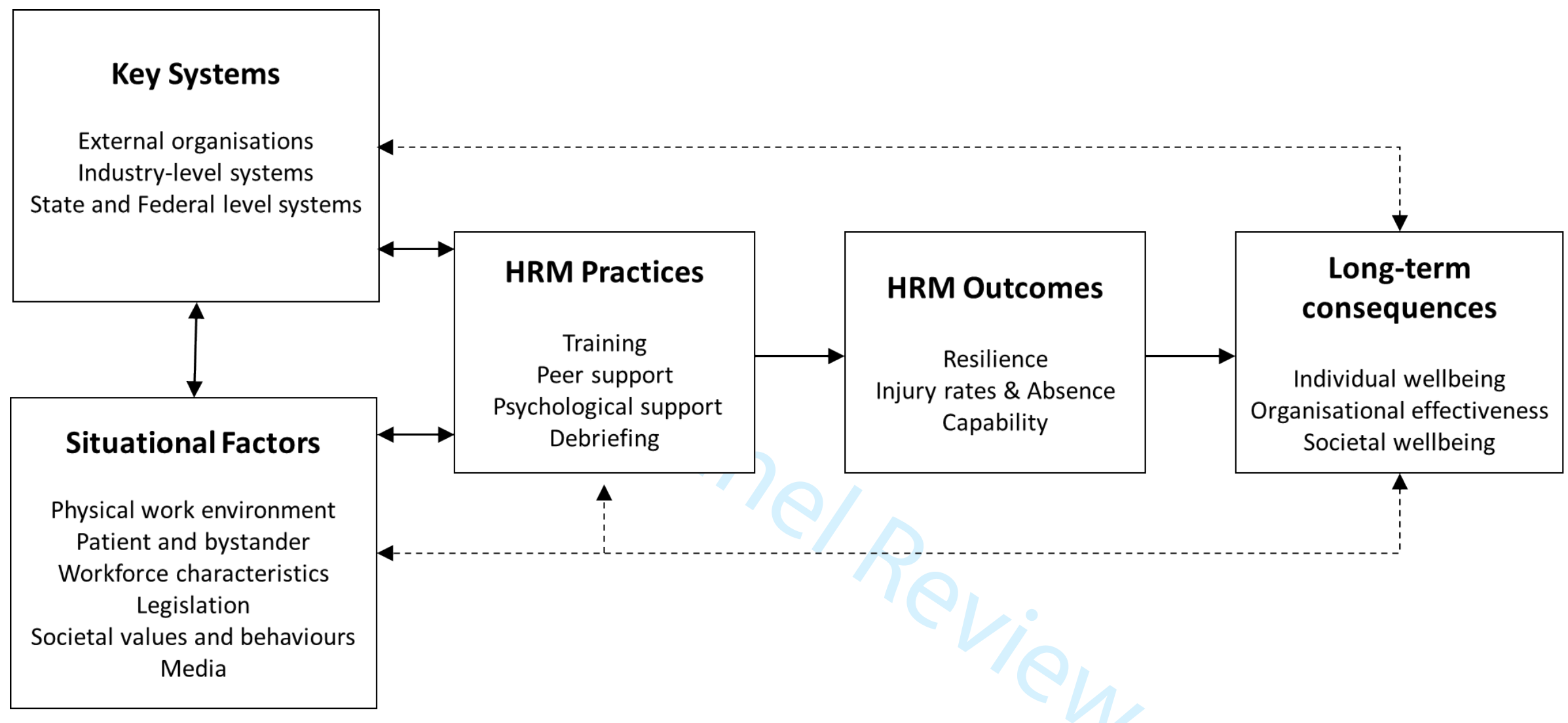

Figure 1. A conceptual map of HRM and violence in the ambulance sector (adapted from Beer et al., 1984) 


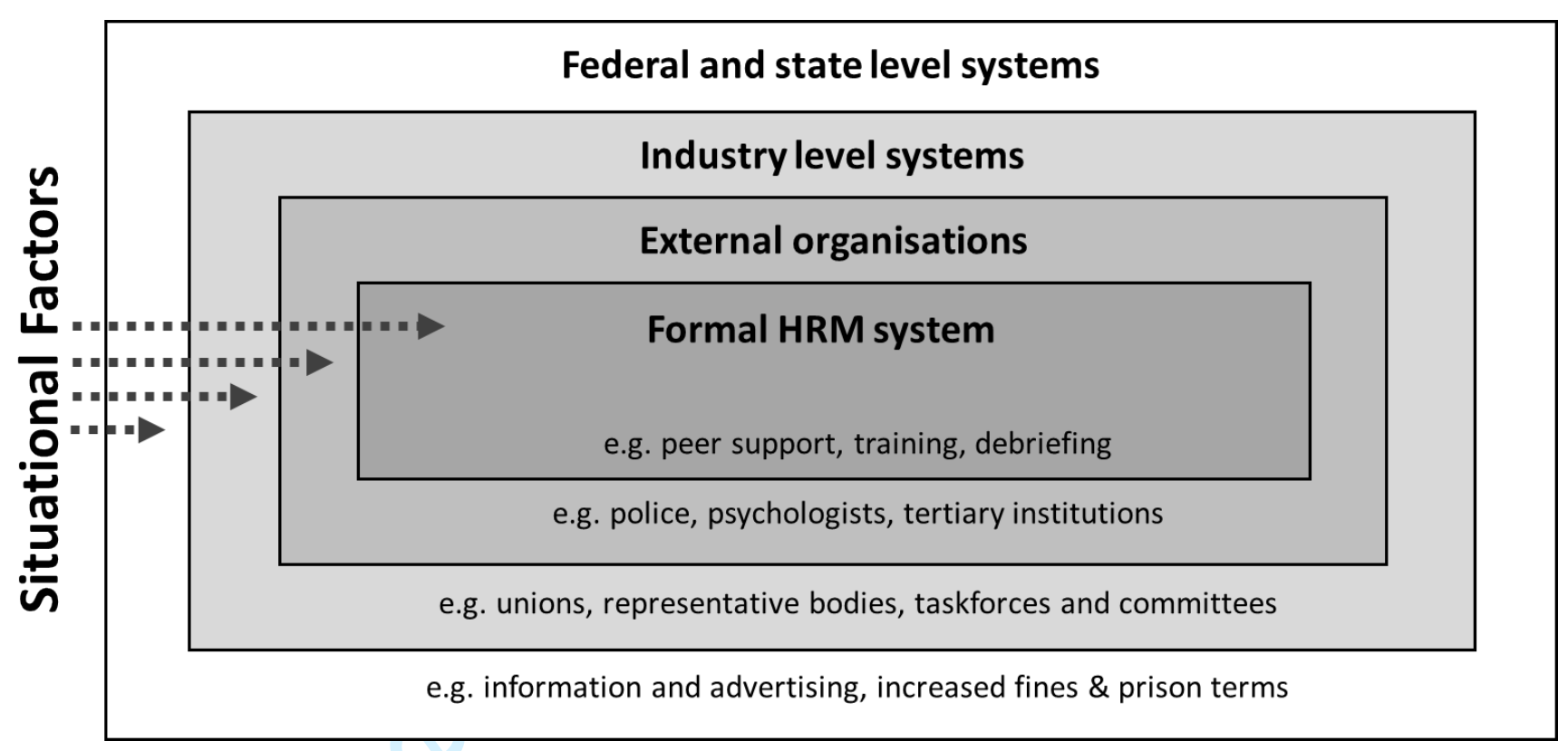

Figure 2. Multi-layer framework of system responses to work-related violence 
Appendices

Appendix 1. List of Interviewees

Interview 1 East Service, Frontline Manager

Interview 2 East Service, Paramedic

Interview 3 East Service, Dispatch Officer

Interview 4 East Service, Paramedic

Interview 5 East Service, Paramedic

Interview 6 East Service, Paramedic

Interview 7 East Service, Paramedic

Interview 8 East Service, Paramedic

Interview 9 South Service, Paramedic

Interview 10 East Service, Paramedic

Interview 11 East Service, Clinical Educator

Interview 12 East Service, Paramedic

Interview 13 East Service, Dispatch Officer

Interview 14 East Service, Paramedic

Interview 15 East Service, Paramedic

Interview 16 East Service, Frontline Manager

Interview 17 East Service, Frontline Manager

Interview 18 North Service, Union Leader

Interview 19 North Service, Paramedic

Interview 20 North Service, Paramedic

Interview 21 North Service, Paramedic

Interview 22 North Service, Paramedic

Interview 23 North Service, Paramedic

Interview 24 North Service, Paramedic

Interview 25 North Service, Paramedic

Interview 26 North Service, Manager Ops

Interview 27 North Service, Manager HR

Interview 28 South Service, Paramedics

Interview 29 South Service, Paramedic

Interview 30 South Service, Dispatch Officer

Interview 31 South Service, Paramedic

Interview 32 South Service, Paramedic

Interview 33 South Service, Paramedic

Interview 34 South Service, Paramedic

Interview 35 South Service, Paramedic

Interview 36 South Service, Paramedic
Interview 37 South Service, CEO

Interview 38 South Service, Paramedic

Interview 39 South Service, Paramedic

Interview 40 South Service, Paramedic

Interview 41 South Service, Paramedic

Interview 42 South Service, Paramedic

Interview 43 South Service, Paramedic

Interview 44 South Service, Paramedic

Interview 45 South Service, Paramedic

Interview 46 South Service, Paramedic

Interview 47 South Service, Paramedic

Interview 48 South Service, Paramedics

Interview 49 East Service, Union Rep.

Interview 50 East Service, Union Rep.

Interview 51 East Service, Union Rep.

Interview 52 East Service, Union Leader

Interview 53 South Service, Frontline Manager

Interview 54 South Service, Director Operations

Interview 55 South Service, Manager Ops.

Interview 56 South Service, Manager HR

Interview 57 South Service, Manager Ops.

Interview 58 South Service, Union Leader

Interview 59 South Service, Manager Ops.

Interview 60 South Service, Org. Psychologist

Interview 61 South Service, Paramedic

Interview 62 East Service, Manager Clinical Ed.

Interview 63 East Service, Manager Clinical Ed.

Interview 64 East Service, Director Operations

Interview 65 East Service, Director Employee Support

Interview 66 East Service, Director Finance

Interview 67 East Service, Director HR

Interview 68 East Service, Manager Clinical Ed.

Interview 69 East Service, Manager Clinical Ed.

Interview 70 East Service, Executive Director

Interview 71 East Service, Regional Manager

Interview 72 East Service, Director Planning \& Perform. 